Elsevier Editorial System(tm) for Journal of Volcanology and Geothermal Research

Manuscript Draft

Manuscript Number:

Title: Daily monitoring of Ecuadorian volcanic degassing from space

Article Type: Special Issue: Ecuadorian Andes

Section/Category:

Keywords: OMl; sulfur dioxide; volcanic degassing; Ecuador

Corresponding Author: Dr. Simon A. Carn,

Corresponding Author's Institution: University of Maryland, Joint Center for Earth Systems Tech

First Author: Simon A. Carn

Order of Authors: Simon A. Carn; Arlin J Krueger; Nickolay A Krotkov; Santiago Arellano; Kai Yang

Manuscript Region of Origin:

Abstract: Daily measurements of sulfur dioxide (SO2) emissions from active volcanoes in Ecuador and southern Colombia between September 2004 and September 2006, derived from the Ozone Monitoring Instrument (OMI) on NASA's EOS/Aura satellite, are presented. OMI is an ultraviolet/visible spectrometer with an unprecedented combination of spatial and spectral resolution, and global coverage, that permit daily measurements of passive volcanic degassing from space. We use non-interactive processing methods to automatically extract daily SO2 burdens and information on $\mathrm{SO} 2$ sources from the OMI datastream. Maps of monthly average SO2 vertical columns retrieved by OMI over Ecuador and S. Colombia are also used to illustrate variations in regional SO2 loading and to pinpoint sources. The dense concentration of active volcanoes in Ecuador provides a stringent test of OMI's ability to distinguish SO2 from multiple emitting sources. Our analysis reveals that Tungurahua, Reventador and Galeras were responsible for the bulk of the $\mathrm{SO} 2$ emissions in the region in the timeframe of our study, with no significant SO2 discharge detected 
from Sangay. At Galeras and Reventador, we conclude that OMI can detect variations in SO2 release related to cycles of conduit sealing and degassing, which are a critical factor in hazard assessment. The OMI SO2 data for Reventador are the most extensive sequence of degassing measurements yet available for this remote volcano, which dominated regional SO2 production in June - August 2005. At Tungurahua, the OMI measurements span the waning stage of one eruptive cycle and the beginning of another. We observe a good qualitative agreement between OMI-derived SO2 burdens and coincident ground-based SO2 flux measurements at Tungurahua, and note increasing SO2 emissions in the months prior to large explosive eruptions of the volcano in July and August 2006. Cumulative SO2 loadings measured by OMI yield a total of $\sim 1.16 \mathrm{Tg} \mathrm{SO} 2$ emitted by volcanoes on mainland Ecuador/S. Colombia between September 2004 and September 2006; as much as 95\% of this SO2 may originate from non-eruptive degassing. Approximate apportionment of the total SO2 loading indicates that $\sim 40 \%$ originated from Tungurahua, with $\sim 30 \%$ supplied by both Reventador and Galeras. Inclusion of SO2 production by eruptions of Fernandina and Sierra Negra (Galápagos Islands) in May and October 2005, respectively, yields a total SO2 release of $\sim 3.24 \mathrm{Tg}$ in this period. These measurements of volcanic SO2 degassing in Ecuador confirm OMl's potential as an effective, economical and risk-free tool for daily monitoring of $\mathrm{SO} 2$ emissions from hazardous volcanoes. 


\title{
Daily monitoring of Ecuadorian volcanic degassing from space
}

S. A. Carn and A. J. Krueger

Joint Center for Earth Systems Technology (JCET), University of Maryland Baltimore County (UMBC), Baltimore, MD 21250, USA

S. Arellano

Instituto Geofísico - Escuela Politécnica Nacional, Ladrón de Guevara e11-253, Apartado 2759, Quito, Ecuador

N. A. Krotkov and K. Yang

Goddard Earth Sciences and Technology (GEST) Center, University of Maryland Baltimore

County (UMBC), Baltimore, MD 21250, USA

\begin{abstract}
Daily measurements of sulfur dioxide $\left(\mathrm{SO}_{2}\right)$ emissions from active volcanoes in Ecuador and southern Colombia between September 2004 and September 2006, derived from the Ozone Monitoring Instrument (OMI) on NASA's EOS/Aura satellite, are presented. OMI is an ultraviolet/visible spectrometer with an unprecedented combination of spatial and spectral resolution, and global coverage, that permit daily measurements of passive volcanic degassing from space. We use non-interactive processing methods to automatically extract daily $\mathrm{SO}_{2}$ burdens and information on $\mathrm{SO}_{2}$ sources from the OMI datastream. Maps of monthly average $\mathrm{SO}_{2}$ vertical columns retrieved by OMI over Ecuador and S. Colombia are also used to illustrate variations in regional $\mathrm{SO}_{2}$ loading and to pinpoint sources. The dense concentration of active volcanoes in Ecuador provides a stringent test of OMI's ability to distinguish $\mathrm{SO}_{2}$ from multiple emitting sources. Our analysis reveals that Tungurahua, Reventador and Galeras were responsible for the bulk of the $\mathrm{SO}_{2}$ emissions in the region in the timeframe of our study, with no significant $\mathrm{SO}_{2}$ discharge detected from Sangay. At Galeras and Reventador, we conclude that OMI can detect variations in $\mathrm{SO}_{2}$ release related to cycles of conduit sealing and degassing, which are a critical factor in hazard assessment. The $\mathrm{OMI} \mathrm{SO}$ data for Reventador are the most extensive
\end{abstract}


sequence of degassing measurements yet available for this remote volcano, which dominated regional $\mathrm{SO}_{2}$ production in June - August 2005. At Tungurahua, the OMI measurements span the waning stage of one eruptive cycle and the beginning of another. We observe a good qualitative agreement between OMI-derived $\mathrm{SO}_{2}$ burdens and coincident ground-based $\mathrm{SO}_{2}$ flux measurements at Tungurahua, and note increasing $\mathrm{SO}_{2}$ emissions in the months prior to large explosive eruptions of the volcano in July and August 2006. Cumulative $\mathrm{SO}_{2}$ loadings measured by OMI yield a total of $\sim 1.16 \mathrm{Tg} \mathrm{SO}_{2}$ emitted by volcanoes on mainland Ecuador/S. Colombia between September 2004 and September 2006; as much as 95\% of this $\mathrm{SO}_{2}$ may originate from non-eruptive degassing. Approximate apportionment of the total $\mathrm{SO}_{2}$ loading indicates that $\sim 40 \%$ originated from Tungurahua, with $\sim 30 \%$ supplied by both Reventador and Galeras. Inclusion of $\mathrm{SO}_{2}$ production by eruptions of Fernandina and Sierra Negra (Galápagos Islands) in May and October 2005, respectively, yields a total $\mathrm{SO}_{2}$ release of $\sim 3.24 \mathrm{Tg}$ in this period. These measurements of volcanic $\mathrm{SO}_{2}$ degassing in Ecuador confirm OMI's potential as an effective, economical and risk-free tool for daily monitoring of $\mathrm{SO}_{2}$ emissions from hazardous volcanoes.

\section{Introduction}

Ecuador can claim to have experienced the most dramatic recent upsurge in volcanic unrest of any nation burdened by active volcanism. Little more than a decade saw significant eruptions from Guagua Pichincha in 1998-99 (e.g., Smithsonian Institution, 1999), the reactivation of Tungurahua in 1999 (Ruiz et al., 2006), one of Ecuador's largest historical eruptions at Reventador in 2002 (Hall et al., 2004), in addition to renewed activity at Galeras (Colombia), close to Ecuador's northern border, beginning in 1988 (Cortés and Raigosa, 1997). Several other Ecuadorian volcanoes are potentially active or require regular surveillance: Sangay has been continuously active since 1628 (Monzier et al., 1999), and little more than a century ago 
Cotopaxi was persistently active whilst Tungurahua was dormant (Whymper, 1892). This dense concentration of hazardous volcanoes presents challenges for ground-based monitoring efforts, exacerbated by Ecuador's fickle climate and challenging terrain, including several glaciated volcanic summits situated at altitudes of $\sim 6 \mathrm{~km}$.

Satellite remote sensing offers obvious attractions as a means of monitoring Ecuador's volcanoes, including a synoptic perspective and the typically low cost of data. Progress has been made in measuring several of the classic indicators of volcanic unrest (e.g., gas emissions, deformation, thermal anomalies) from space with sufficient precision and temporal resolution to permit timely detection of perturbations in a volcanic system. Examples include near real-time thermal infrared (IR) imaging of volcanoes by IR sensors on geostationary and polar-orbiting satellites (e.g., Harris et al., 2000; Wright et al., 2004), and operational tracking of volcanic ash clouds for aviation hazard mitigation (e.g., Tupper et al., 2004). Until recently however, satellite measurements of volcanic sulfur dioxide $\left(\mathrm{SO}_{2}\right)$ emissions, a key yardstick at many restless volcanoes, were limited to large eruptions, with ground-based or airborne measurements fulfilling most routine $\mathrm{SO}_{2}$ monitoring requirements. Here we introduce a significant advance offered by the Ozone Monitoring Instrument (OMI), an ultraviolet/visible (UV/VIS) sensor launched in July 2004 on NASA's Earth Observing System (EOS) Aura satellite. OMI has an unprecedented combination of footprint size, spectral resolution and swath width that permits daily, contiguous global mapping of $\mathrm{SO}_{2}$ at all altitudes from the planetary boundary layer (PBL) to the stratosphere. Due to these unique characteristics, OMI has achieved the first daily, spacebased measurements of passive volcanic degassing.

The purpose of this paper is twofold. Using $\mathrm{OMI} \mathrm{SO}_{2}$ data collected over Ecuador and southern Colombia (Galeras volcano) from September 2004 - September 2006, we demonstrate that valuable information on trends in, and sources of, volcanic $\mathrm{SO}_{2}$ emissions can be extracted 
from largely automated processing of daily OMI data. Galeras is included in the analysis as its $\mathrm{SO}_{2}$ emissions frequently drift over northern Ecuador. We also derive an estimate of total $\mathrm{SO}_{2}$ emissions from active volcanoes in the region in this timeframe.

\section{Volcanic degassing in the northern Andes}

Volcanoes of the Andean Northern Volcanic Zone with reported degassing data are notable for elevated sulfur emissions. Nevado del Ruiz (Colombia) released $\sim 0.75 \mathrm{Tg}$ of $\mathrm{SO}_{2}$ in sulfur-rich eruptions in 1985 (Krueger et al., 1990), and subsequently sustained $\mathrm{SO}_{2}$ fluxes of $\sim 10^{3}-10^{4}$ tons day $^{-1}\left(\mathrm{t} \mathrm{d}^{-1}\right)$ until at least the early 1990s (Williams et al., 1990; Smithsonian Institution, 1991). Following reactivation in 1988, Galeras (Colombia) initially discharged $3000-5000 \mathrm{t} \mathrm{d}^{-1}$ or more of $\mathrm{SO}_{2}$, where after fluxes declined to $300 \mathrm{t} \mathrm{d}^{-1}$ by 1995 (Zapata et al., 1997). In Ecuador, Reventador's explosive eruption on 3 November 2002 produced $\sim 0.1 \mathrm{Tg}$ of $\mathrm{SO}_{2}$, and in the ensuing 4 weeks vigorous degassing, detected from space by the Total Ozone Mapping Spectrometer (TOMS), emitted a further $\sim 0.22 \mathrm{Tg}$ (Dalton et al., manuscript in preparation). Tungurahua awoke in August 1999 following $~ 80$ years of repose, and until early 2000 produced high $\mathrm{SO}_{2}$ fluxes that occasionally exceeded $10^{4} \mathrm{t} \mathrm{d}^{-1}$ (Arellano et al., this volume). Between 2001 and early 2005 the volcano exhibited four roughly year-long eruptive cycles, defined by Ruiz et al. (2006) on the basis of explosion frequency, which were characterized by fluctuating $\mathrm{SO}_{2}$ emissions averaging $\sim 1500 \mathrm{t} \mathrm{d}^{-1}$ (Arellano et al., this volume). All of these volcanoes have released the vast majority of their volatiles via non-eruptive or passive degassing.

Most of the $\mathrm{SO}_{2}$ data summarized above are derived from intermittent ground-based or airborne COSPEC or differential optical absorption spectroscopy (DOAS) measurements, with TOMS satellite data supplying total $\mathrm{SO}_{2}$ estimates for the large Ruiz and Reventador eruptions, and a few of the larger explosions of Tungurahua (Carn et al., 2003). There is also an extensive 
TOMS database of $\mathrm{SO}_{2}$ emissions from eruptions in the Ecuadorian territory of the Galápagos Islands from 1979-2005, which will be reported elsewhere (Head et al., manuscript in preparation). Neither TOMS nor other more sensitive satellite instruments such as the Global Ozone Monitoring Experiment (GOME) and the Scanning Imaging Absorption Spectrometer for Atmospheric Chartography (SCIAMACHY), which have also measured volcanic $\mathrm{SO}_{2}$ emissions over Ecuador (Afe et al., 2004; Khokhar et al., 2005), are capable of providing daily observations of tropospheric $\mathrm{SO}_{2}$ plumes generated by passive degassing. At the time of writing the only Ecuadorian volcano subject to frequent ground-based gas monitoring is Tungurahua, which has a UV spectrometer network deployed on its flanks for static scanning measurements of $\mathrm{SO}_{2}$ emissions (Arellano et al., this volume).

\section{The Ozone Monitoring Instrument}

OMI is a UV/VIS (270-500 nm) nadir solar backscatter spectrometer in polar orbit on Aura with a local afternoon equatorial overpass at 13:45 (Levelt et al. 2005a). The instrument provides daily, contiguous global mapping of ozone, $\mathrm{SO}_{2}$ and other trace gases $\left(\mathrm{NO}_{2}, \mathrm{BrO}, \mathrm{HCHO}\right)$ with a nadir spatial resolution of $13 \times 24 \mathrm{~km}$ (Levelt et al., 2005b). OMI's UV-2 channel (306-380 nm), which is used for $\mathrm{SO}_{2}$ retrievals, has an average spectral resolution of $0.45 \mathrm{~nm}$ (Levelt et al., 2005a). The combination of full UV-2 coverage at high spectral resolution and small footprint size permits $\mathrm{SO}_{2}$ retrievals with unprecedented sensitivity for a space-based instrument.

Several different retrieval schemes can be used to derive $\mathrm{SO}_{2}$ column amounts from OMI radiances. Here, we use the Band Residual Difference (BRD) algorithm described by Krotkov et al. (2006). The $\mathrm{BRD}$ technique uses calibrated residuals at $\mathrm{SO}_{2}$ absorption band centers in the 310-315 nm wavelength range, produced by the operational OMI ozone algorithm, to generate a total column $\mathrm{SO}_{2}$ measurement. While not optimal, the $\mathrm{BRD}$ retrieval produces a two orders of 
magnitude improvement in the minimum detectable amount of $\mathrm{SO}_{2}$ relative to TOMS, permitting daily measurements of passive volcanic degassing (Krotkov et al., 2006). At the time of writing, OMI BRD $\mathrm{SO}_{2}$ columns have not been rigorously validated, but first-order comparisons between $\mathrm{SO}_{2}$ burdens derived from $\mathrm{BRD}$ retrievals, other satellite $\mathrm{SO}_{2}$ retrievals (e.g., TOMS, Atmospheric Infrared Sounder [AIRS]), and ground-based $\mathrm{SO}_{2}$ measurements at degassing volcanoes, have shown no major discrepancies to date (S.A. Carn, unpublished data).

Accurate retrieval of vertical $\mathrm{SO}_{2}$ columns requires knowledge of the $\mathrm{SO}_{2}$ vertical profile, which governs the air mass factor (AMF) used to convert slant $\mathrm{SO}_{2}$ columns (SC) to vertical columns ( $\mathrm{VC}=\mathrm{SC} / \mathrm{AMF})$. This information is seldom available at the time of measurement, so our initial approach for $\mathrm{OMI} \mathrm{SO}$ retrievals has been to generate three $\mathrm{SO}_{2}$ column amounts for three generalized $\mathrm{SO}_{2}$ profiles: $\mathrm{SO}_{2}$ distributed evenly in the $\mathrm{PBL}$ (below $\sim 3 \mathrm{~km}$ altitude); an $\mathrm{SO}_{2}$ layer centered at $5 \mathrm{~km}$ altitude; and a layer centered at $15 \mathrm{~km}$ altitude. These cases are intended to represent typical $\mathrm{SO}_{2}$ vertical distributions for low altitude volcanic degassing or anthropogenic pollution, volcanic degassing in the free troposphere, and high-altitude eruption clouds, respectively. Given the high elevation of the Ecuadorian and Colombian volcanoes (the mean altitude of Galeras, Reventador, Tungurahua and Sangay is $\sim 4.5 \mathrm{~km}$ ), we use the $5 \mathrm{~km}$ case in this analysis. Volcanic plumes will typically rise above vent altitude, but since the exact plume altitude is rarely known, this is a necessary assumption. Underestimating the altitude of the $\mathrm{SO}_{2}$ will usually result in an overestimate of the $\mathrm{SO}_{2}$ amount, and vice versa.

No attempt has been made here to account for the effects of aerosol (ash and sulfate) on $\mathrm{UV} \mathrm{SO}_{2}$ retrievals, which can be significant. This is a goal of future work, but for this analysis of predominantly non-eruptive, ash-poor plumes we assume that associated errors will be considerably less than the maximum $30 \%$ error on TOMS $\mathrm{SO}_{2}$ retrievals of ash-laden explosive eruption clouds (Krueger et al., 1995). 


\section{OMI data analysis}

Our OMI analysis software generates daily maps of $\mathrm{SO}_{2}$ vertical column densities (VCDs) for any region of the globe, and can also calculate cumulative or average $\mathrm{SO}_{2}$ maps for any time period (e.g., Fig. 1). The average maps in Figure 1 show the geographic region selected for our analysis of Ecuador and S. Colombia. Readers interested in daily $\mathrm{SO}_{2}$ maps, not presented here due to space limitations, are requested to contact the authors.

The main goal of this work was to extract volcanological data, such as $\mathrm{SO}_{2}$ cloud mass and the likely source of observed $\mathrm{SO}_{2}$ emissions, from the daily OMI observations with a minimum of analyst input or manual image analysis. Interactive, offline calculation of daily $\mathrm{SO}_{2}$ cloud tonnages, the approach adopted with TOMS data, is impractical with OMI as the $\mathrm{SO}_{2}$ cloud detection rate is much higher. We have therefore tested three techniques to derive $\mathrm{SO}_{2}$ burdens non-interactively from subsets of OMI data over pre-defined regions i.e., to isolate the volcanic $\mathrm{SO}_{2}$ signal from omnipresent background noise resulting from cumulative measurement, modeling, and calibration errors. These are briefly described below.

The Fixed Threshold (FT) method is the simplest burden derivation procedure, using only the volcanic region as input. A constant threshold $\mathrm{SO}_{2} \mathrm{VCD}$ (in Dobson Units [DU]) value (T) is assigned, and the reported $\mathrm{SO}_{2}$ burden is the total $\mathrm{SO}_{2}$ mass retrieved in all OMI pixels within the region that contain $\geq T \mathrm{DU}$ of $\mathrm{SO}_{2}$. For the analysis presented here, $T=0.6 \mathrm{DU}$ was used in calculations using the FT method. This is approximately equal to noise at the $3 \sigma$ level observed in $\mathrm{BRD}$ volcanic $\mathrm{SO}_{2}$ retrievals in $\mathrm{SO}_{2}$-free regions (Krotkov et al., 2006).

The Background Subtraction (BS) technique requires selection of two (or more) nominally $\mathrm{SO}_{2}$-free background regions adjacent to the volcanic region. Total $\mathrm{SO}_{2}$ burdens are 
calculated for each data subset, then the background $\mathrm{SO}_{2}$ burdens are normalized to the area of the volcanic region, averaged, and the result is subtracted from the total $\mathrm{SO}_{2}$ mass measured in the volcanic region. This is the approach used historically for derivation of $\mathrm{SO}_{2}$ cloud tonnages from TOMS data (Krueger et al., 1995).

Finally, the Variable Threshold (VT) method utilizes two nominally $\mathrm{SO}_{2}$-free background regions close to the selected volcanic region. Using the mean $\left(\bar{x}_{\mathrm{n}}\right)$ and standard deviation $\left(\sigma_{\mathrm{n}}\right)$ of $\mathrm{SO}_{2} \mathrm{VCDs}$ retrieved on each day in background region $n$, a threshold value $(T)$ equal to $\frac{1}{2}\left(\left(\bar{x}_{1}+3 \sigma_{1}\right)+\left(\bar{x}_{2}+3 \sigma_{2}\right)\right)$ is calculated. The $\mathrm{SO}_{2}$ burden reported for the volcanic region is then the total $\mathrm{SO}_{2}$ mass retrieved in all OMI pixels enclosed by the region that contain $\geq T \mathrm{DU}$ of $\mathrm{SO}_{2}$.

The VT method intrinsically accounts for any daily variations in retrieval noise and/or bias, and is assumed to provide the most robust indication of whether $\mathrm{SO}_{2}$ is present in statistically significant amounts. However, this method probably underestimates the total mass of $\mathrm{SO}_{2}$ present. In assessing total volcanic $\mathrm{SO}_{2}$ emissions for this study, we therefore use the VT results to identify the existence of volcanic $\mathrm{SO}_{2}$ in the scene, but take the largest corresponding $\mathrm{SO}_{2}$ burden returned by any method (VT, $\mathrm{FT}$ or $\mathrm{BS}$ ) as the total $\mathrm{SO}_{2}$ amount present on that day.

We also attempt to identify the source of the strongest $\mathrm{SO}_{2}$ emissions observed on each day (Fig. 2), exploiting OMI's good spatial resolution. The source is defined here as the closest active volcano to the center coordinates of the OMI pixel containing the maximum retrieved $\mathrm{SO}_{2}$ VCD. Volcanoes located more than $50 \mathrm{~km}$ from the $\mathrm{SO}_{2}$ maximum are excluded; this is somewhat arbitrary but associating $\mathrm{SO}_{2}$ plumes with sources in Ecuador without a-priori knowledge or image analysis is challenging due to the high density of volcanoes. Using predicted winds to constrain $\mathrm{SO}_{2}$ advection during the $\sim 24$ hours of transport between consecutive OMI overpasses gives distances that greatly exceed that between adjacent volcanoes, rendering the 
source ambiguous (e.g., wind speeds of 5-15 knots imply 220-670 km of transport in 24 hours). Hence the source identification process used here is typically only valid for contiguous $\mathrm{SO}_{2}$ plumes physically connected to their source, and not for detached, drifting $\mathrm{SO}_{2}$ clouds. For the same reasons, when two or more volcanoes are degassing simultaneously we do not attempt to allocate fractions of the total measured $\mathrm{SO}_{2}$ burden to specific sources, although this can sometimes be done interactively and may also be possible non-interactively with more sophisticated image analysis techniques.

Most of the $\mathrm{SO}_{2}$ detected by OMI over Ecuador and $\mathrm{S}$. Colombia during the study period (6 September 2004 - 30 September 2006) was the product of non-eruptive degassing. However, two larger eruptions of Tungurahua in July and August 2006 discharged $\mathrm{SO}_{2}$ clouds that extended beyond the limits of the geographic region shown in Figure 1 and these were analyzed offline (Table 1). In addition, two of the largest eruptions in Ecuadorian territory during this period occurred at Fernandina and Sierra Negra (Galápagos Islands) in May and October 2005, respectively. Total $\mathrm{SO}_{2}$ production for these eruptions, which emitted more $\mathrm{SO}_{2}$ than any single eruption in mainland Ecuador in 2004-2006, is reported here for completeness (Table 1), but detailed analysis of these events is deferred to later papers.

\section{Results and discussion}

Monthly average $\mathrm{OMI} \mathrm{SO}_{2}$ maps for Ecuador and S. Colombia are shown in Fig. 1. These depict relative levels of degassing at the region's volcanoes during each month. Time-series plots of OMI $\mathrm{SO}_{2}$ burdens over the region generated using the FT, BS and VT methods described above are shown in Fig. 2, in which the source volcano identified during data processing is also indicated. The source(s) of $\mathrm{SO}_{2}$ emissions charted in Fig. 2 can also be deduced by crossreferencing with the appropriate map in Fig. 1. Note the spikes in $\mathrm{SO}_{2}$ burden associated with 
drifting $\mathrm{SO}_{2}$ clouds from eruptions of Fernandina, Sierra Negra and Soufriere Hills, Montserrat, when in transit over Ecuador (Fig. 2). The similar magnitude of $\mathrm{SO}_{2}$ burdens calculated using the FT and VT methods (Fig. 2a, c) indicates that our choice of 0.6 DU as a fixed noise threshold was reasonable in this case.

We stress that the $\mathrm{SO}_{2}$ amounts measured by OMI and displayed in Fig. 2 are burdens and not fluxes. The entire region demarcated in Fig. 1 is sensed by OMI in $\sim 2$ minutes during a wellplaced single orbit, and in these cases the $\mathrm{SO}_{2}$ measured during an OMI overpass can be considered an 'instantaneous' $\mathrm{SO}_{2}$ burden. Unless accurate data are available on the timing of the event responsible for the observed $\mathrm{SO}_{2}$, the temporal dimension required to convert this to a flux is lacking. If the region straddles two OMI orbits, then one orbital period ( 90 minutes) elapses between measurements during the first, easternmost, orbit and the next, but even in these cases the same $\mathrm{SO}_{2}$ cloud is never measured twice daily at equatorial latitudes (note that we do not make a distinction between overpass configurations here). A rigorous analysis of the expected relationship between OMI-derived $\mathrm{SO}_{2}$ burdens and correlative $\mathrm{SO}_{2}$ flux measurements requires data that are presently unavailable (e.g., accurate plume altitudes, daily meteorological data, a model to simulate conversion of $\mathrm{SO}_{2}$ to sulfate and wet/dry deposition in a tropospheric volcanic plume). Based on experience to date, we believe that $\mathrm{OMI}$-derived $\mathrm{SO}_{2}$ burdens are a good proxy for $\mathrm{SO}_{2}$ fluxes at the source, with optimal correspondence in magnitude expected for plumes above the PBL in cloud-free conditions where the $\mathrm{SO}_{2}$ lifetime is close to 1 day.

In the following summary we discuss the patterns of $\mathrm{SO}_{2}$ degassing revealed by the OMI measurements (Fig. 1, 2) separately for each of the four volcanoes responsible for the emissions: Galeras, Reventador, Tungurahua and Sangay. Clearly, our decision to attribute the observed $\mathrm{SO}_{2}$ emissions to these volcanoes is influenced by external knowledge and is not solely based on the satellite data; for example, $\mathrm{SO}_{2}$ originating from Galeras and Reventador was frequently observed 
over Guagua Pichincha, but in the absence of reports of substantive activity at this volcano we eliminated it from our list of potential sources. As with all volcanological data, the $\mathrm{OMI} \mathrm{SO}_{2}$ measurements are best interpreted in conjunction with other available monitoring parameters.

\subsection{Galeras}

Activity at Galeras was relatively low from 1994 until June 2004, but increased in July-August 2004 when a series of explosive events occurred (Smithsonian Institution, 2005e). Based on seismic tremor, September through November 2004 saw continuous gas and ash emissions from Galeras (Smithsonian Institution, 2005e), and this is confirmed by clear $\mathrm{SO}_{2}$ plume signals in corresponding OMI monthly averages (Fig. 1), and by its selection as the predominant $\mathrm{SO}_{2}$ source at this time (Fig. 2). An explosive eruption of Galeras on 21 November 2004 coincided with an OMI data gap from 18 November - 2 December (Fig. 2; note that such lengthy data gaps are highly unusual and only occurred early in the Aura mission due to instrument testing). OMI measurements indicate reduced degassing from late 2004 into 2005 (Fig. 1) and this is supported by available reports (Smithsonian Institution, 2005e).

Long-period seismicity, indicative of pressurized fluid flow, triggered evacuations around Galeras in mid-November 2005, and a small explosive eruption occurred on 24 November (Smithsonian Institution, 2006a). Inspection of daily $\mathrm{SO}_{2}$ maps reveals that OMI began measuring increased $\mathrm{SO}_{2}$ emissions from Galeras on 25 November; this is also apparent from the source selection and a clear increase in $\mathrm{SO}_{2}$ burdens over the region at this time (Fig. 2a, c), and is presumably linked to open-system degassing following the vent-clearing explosion on 24 November. Elevated $\mathrm{SO}_{2}$ emissions continued through February 2006 (reported $\mathrm{SO}_{2}$ fluxes 
ranged from 200-1500 $\mathrm{t} \mathrm{d}^{-1}$ in early 2006; Smithsonian Institution, 2006a), shown by high average $\mathrm{SO}_{2}$ VCDs west of Galeras in this period (Fig. 1).

By April-May 2006, growth of a lava dome in Galeras' crater (Smithsonian Institution, 2006c) had evidently curbed the $\mathrm{SO}_{2}$ emissions (Fig. 1, 2). Further evacuations and small explosive eruptions followed on 12 July (Smithsonian Institution, 2006c). Significantly, although OMI detected a small $\mathrm{SO}_{2}$ cloud produced by the 12 July event (Galeras was picked as the strongest $\mathrm{SO}_{2}$ source on that day; Fig. 2a), we observe no elevated $\mathrm{SO}_{2}$ emissions from Galeras in the ensuing $\sim 2$ months (Fig. 1), in contrast to the period following the July-August 2004 and November 2005 eruptions. A preliminary inference is that either the source of the July 2006 explosions was shallower, perhaps triggered by crystallization of magma in the lava dome, and as such did not release volatiles from deeper in the system, or that the volatile reservoir at depth had been depleted by prior degassing.

In summary, we conclude that OMI measurements are able to detect cycles of degassing and conduit sealing at Galeras. Monitoring cyclic degassing, sealing, pressurization (manifested by long-period seismicity) and explosive eruptions is a critical aspect of hazard assessment at the volcano (Stix et al., 1993; Fischer et al., 1994). Incorporating daily $\mathrm{OMI} \mathrm{SO}_{2}$ data into existing monitoring strategies would therefore provide some useful additional constraints on the status of the volcano and also on models of degassing and explosive eruptions at Galeras (e.g., Stix et al., 1993, 1997).

\subsection{Reventador}

Reventador is a remote, poorly monitored volcano and OMI measurements of its $\mathrm{SO}_{2}$ emissions provide new insights into its activity in 2004-2006. The initial appearance of a $\mathrm{SO}_{2}$ signal at 
Reventador in November 2004 (Fig. 1) correlates with renewed lava effusion (the first since 2002) and a dramatic increase in seismicity in early November, followed by visual confirmation of significant degassing on November 10 (Smithsonian Institution, 2004). The subsequent $\sim 6$ months saw little significant detectable change in emissions (Fig. 1); inspection of daily OMI data shows sporadic $\mathrm{SO}_{2}$ plumes from Reventador in this period, though given the volcano's location on the tropical eastern flank of the Cordillera Real it is possible that cloud cover and/or wet deposition of $\mathrm{SO}_{2}$ masked more persistent degassing.

A major increase in measurable $\mathrm{SO}_{2}$ output from Reventador occurred in June 2005 (Fig. $1,2)$, and four distinct phases of elevated emissions were detected by OMI before the end of August 2005 (3-16 June, 2-7 July, 20-25 July and 17-30 August; Fig. 2). During this period, $\mathrm{SO}_{2}$ plumes frequently extended large distances from Reventador out across the Pacific Ocean (a vapor/ash plume caused light ashfall in Quito on 8 June; Smithsonian Institution, 2005b), hence the volcano was seldom picked as the strongest $\mathrm{SO}_{2}$ source (Fig. 2) since the locations of $\mathrm{SO}_{2}$ VCD maxima exceeded the $50 \mathrm{~km}$ distance threshold. Strombolian fountaining was reported at Reventador on 11-12 June (Smithsonian Institution, 2005b), when $\mathrm{SO}_{2}$ emissions were elevated (Fig. 2), but this had been supplanted by Vulcanian activity during observations on 16-19 June (Smithsonian Institution, 2005b), when $\mathrm{SO}_{2}$ discharge had declined (Fig. 2). This is consistent with plugging of the conduit, reduced degassing, and increased explosive activity at the end of the 3-16 June phase of gas release. We surmise that before the resumption of significant $\mathrm{SO}_{2}$ degassing on 2 July the conduit plug had been sufficiently weakened by explosive activity to permit higher gas fluxes, or that explosions had begun to tap deeper, more $\mathrm{SO}_{2}$-rich magma. Similar processes may explain the subsequent $\mathrm{SO}_{2}$ degassing cycles observed by OMI, since Strombolian and Vulcanian activity, the former generating voluminous gas plumes, was reported intermittently at Reventador in July and August 2005 (Smithsonian Institution, 2005d). Measured 
$\mathrm{SO}_{2}$ emissions declined substantially in September 2005 (Fig. 1), although explosive activity continued (Smithsonian Institution, 2005d).

Hence, as at Galeras, $\mathrm{OMI} \mathrm{SO}_{2}$ measurements reveal cycles of degassing at Reventador that likely relate to periodic conduit sealing. We note that the $\mathrm{SO}_{2}$ burdens measured in JuneAugust 2005 (Fig. 2) exhibit a striking anti-correlation with contemporaneous seismic event counts reported in Smithsonian Institution (2005d), with $\mathrm{SO}_{2}$ emission peaks occurring during periods of relative seismic quiescence, particularly with respect to hybrid earthquakes. This suggests that seismic events indicative of pressurization were less frequent when $\mathrm{SO}_{2}$ emissions were elevated, as might be expected for a system fluctuating between open and closed states.

\subsection{Tungurahua}

Tungurahua produced the most persistent emissions in the region from September 2004 September 2006, with $\mathrm{SO}_{2}$ apparent in every month (Fig. 1) and the highest incidence of source selection (Fig. 2a). Tungurahua's gas emissions are typically the result of multiple small explosive, jetting and chugging events (Ruiz et al., 2006), which produce emissions that merge to form a continuous tropospheric gas plume. The beginning of our study period captured the latter half of Tungurahua's 2004-2005 eruptive cycle, which peaked in July 2004 and waned early in 2005 (Johnson et al., 2005; Ruiz et al., 2006). This waning cycle appears to be reflected in the OMI $\mathrm{SO}_{2}$ measurements by a reduction in $\mathrm{SO}_{2}$ burdens and in Tungurahua's status as the major $\mathrm{SO}_{2}$ source beginning in March 2005 (Fig. 2a). Low volcanic and seismic activity was reported at Tungurahua from February until mid-July 2005 (Smithsonian Institution, 2005c), although $\mathrm{SO}_{2}$

emissions continued (Fig. 1, 2c), evidently supplied by low-energy degassing. Overall, 2005 was 
deemed the quietest year at Tungurahua since reactivation in 1999, prompting thoughts of a possible cessation of unrest (Smithsonian Institution, 2006d).

However, a new eruptive cycle was heralded by increased $\mathrm{SO}_{2}$ output in December 2005 (Fig. 1, 2), coincident with seismic events that suggested a new injection of magma (Smithsonian Institution, 2006d). A further escalation in seismic activity (long-period earthquake swarms and harmonic tremor) occurred in late March 2006, but without any significant detectable response in $\mathrm{SO}_{2}$ emissions at the surface (Fig. 2), consistent with the deep location of seismic hypocenters (Smithsonian Institution, 2006d). OMI detected increased $\mathrm{SO}_{2}$ discharge from Tungurahua beginning around 9 May (also evident in ground-based $\mathrm{SO}_{2}$ flux data; Fig. 2c), by which time hypocenter depths had shallowed and explosion signals had begun to dominate the seismic record (Smithsonian Institution, 2006d). Reduced $\mathrm{SO}_{2}$ emissions were measured at the end of May, but they recovered to elevated levels, the highest observed at Tungurahua in the timeframe of this analysis, in June and July (Fig. 1), culminating in an explosive eruption on 14 July (Fig. 2; Table 1). At the time this eruption was Tungurahua's largest of 1999-2006, but it was later surpassed in magnitude by the 16 August 2006 eruption (Fig. 2; Table 1). We observe generally increasing $\mathrm{SO}_{2}$ emissions in the $\sim 1.5$ months prior to the 14 July event (clearest in Fig. $2 \mathrm{c}$ ), but no definitive precursor. On 16 August, the OMI overpass at $\sim 1930 \mathrm{UT}, \sim 4.5$ hours before the eruption onset, revealed a significant $\mathrm{SO}_{2}$ plume extending from Tungurahua, which may have marked the inception of activity that escalated into an eruption later that day. The paroxysmal $\mathrm{SO}_{2}$ cloud ( $35 \mathrm{kt}$; Table 1) was measured by OMI on the following day as it drifted away from Tungurahua.

We are encouraged by the good qualitative agreement between the $\mathrm{OMI} \mathrm{SO}_{2}$ data and ground-based $\mathrm{SO}_{2}$ fluxes measured at Tungurahua; particularly between December 2005 and July 2006 when trends in $\mathrm{SO}_{2}$ flux generally correlate with variations in retrieved $\mathrm{SO}_{2}$ VCDs (Fig. 1, 
2c). There are also some clear discrepancies, but detailed intercomparison of the datasets would entail accounting for specific measurement conditions on each day, and is beyond the scope of this paper. In some respects the ground-based and satellite measurements are complementary, with ideal conditions for one technique less favorable for the other, hence OMI data analysis could enhance monitoring of Tungurahua. Additional monitoring strategies are desirable as it has been shown that seismic and acoustic signals may not scale with eruption intensity at the volcano (Johnson et al., 2005).

\subsection{Sangay}

Negligible $\mathrm{SO}_{2}$ emissions were detected from Sangay in 2004-2006; although it is difficult to unambiguously distinguish between Tungurahua and Sangay as the origin of drifting $\mathrm{SO}_{2}$ clouds in southern Ecuador, we assume that Tungurahua would be the more likely source. Sangay was determined to be the source of observed $\mathrm{SO}_{2}$ emissions on only 2 days: 16 and 25 January 2005, but we have no correlative observations to verify this activity. Ash clouds and IR hot spots were detected at Sangay by the Washington VAAC in December 2004 and October 2005 (http://www.ssd.noaa.gov/VAAC/messages.html), so it is apparent that the frequent explosive activity noted by observers of the volcano for centuries (Monzier et al., 1999) continues, but the activity may be predominantly phreatic, releasing little $\mathrm{SO}_{2}$. Furthermore, reports suggest that explosions have become smaller and less frequent since the 1970s, and only weak steaming was observed at the summit in January 2006 (Smithsonian Institution, 2006b). The detection of shortlived, intermittent explosive eruption clouds by polar-orbiting satellites depends strongly on the timing of the eruption relative to the satellite overpass. 


\section{Total $\mathrm{SO}_{2}$ emissions in 2004-2006}

Using the technique described in section 4 , we calculate a cumulative $\mathrm{SO}_{2}$ loading of $\sim 1.16 \mathrm{Tg}$ measured by OMI over Ecuador and S. Colombia between September 2004 and September 2006. This includes the Tungurahua eruptions listed in Table 1, but excludes $\mathrm{SO}_{2}$ associated with drifting $\mathrm{SO}_{2}$ clouds from distant volcanoes (Fig. 2). Including the very productive Galápagos eruptions (Table 1) raises the total $\mathrm{SO}_{2}$ loading to $\sim 3.24 \mathrm{Tg}$. Several factors are unaccounted for in this analysis: meteorological cloud (which would reduce the $\mathrm{SO}_{2} \mathrm{VCD}$ measured by $\mathrm{OMI}$ if located above the $\mathrm{SO}_{2}$; average scene reflectivity is provided in Fig. $2 \mathrm{~b}$ as a proxy for cloud cover), aerosol effects (assumed to introduce errors of $<<30 \%$ ) and AMF changes due to variable $\mathrm{SO}_{2}$ altitude. The latter are the subject to ongoing modeling efforts but accurate assessment is precluded in this case by inadequate knowledge of actual $\mathrm{SO}_{2}$ plume altitudes. To demonstrate the effect (which is non-linear with altitude), modeling of a mid-latitude case indicates that lowering the assumed $\mathrm{SO}_{2}$ altitude from 5 to $3 \mathrm{~km}$ reduces the AMF, and increases the retrieved $\mathrm{SO}_{2} \mathrm{VCD}$, by $\sim 50 \%$.

Using average $\mathrm{SO}_{2}$ VCDs measured by OMI over the entire study period (not shown), we can roughly apportion percentages of the total $\mathrm{SO}_{2}$ loading (excluding the Galápagos eruptions) to the three volcanoes responsible for the bulk of the emissions (Sangay is excluded). This entails subjectively pairing regions of elevated $\mathrm{SO}_{2} \mathrm{VCDs}$ with source volcanoes, and hence is imprecise, but the highly stable easterly wind pattern over Ecuador (Fig. 1) favors this approach. The apportionment indicates that $42 \%$ of the total $\mathrm{SO}_{2}$ loading originated from Tungurahua, with $32 \%$ from Reventador and $26 \%$ from Galeras. As much as $95 \%$ or more of the total $\mathrm{SO}_{2}$ loading was produced by non-eruptive or 'passive' degassing, although whether large fractions of Reventador's and Tungurahua's emissions qualify as truly passive is arguable. 


\section{Summary}

We have demonstrated that daily $\mathrm{OMI} \mathrm{SO}_{2}$ measurements are able to detect important trends in degassing at hazardous volcanoes in Ecuador and S. Colombia. These data are freely available and therefore constitute an economical and effective new resource for risk-free volcano monitoring in such regions. Our data processing techniques permit automated calculation of daily $\mathrm{SO}_{2}$ burdens, and the spatial resolution of OMI permits identification of the major $\mathrm{SO}_{2}$ source when appropriate geometric constraints are applied. The dense concentration of active volcanoes in Ecuador provides a stringent test of these procedures. Issues ripe for further investigation include distinguishing emissions from closely spaced volcanoes (e.g., Sangay and Tungurahua), image processing methods to extract $\mathrm{SO}_{2}$ burdens for discrete clouds, and integration of improved cloud, AMF and aerosol corrections into the measurements.

The daily $\mathrm{OMI} \mathrm{SO}_{2}$ measurements are a rich data source, which we have not attempted to interpret in great detail here. Clearly, the measurements are best interpreted in concert with other parameters. In addition to ground-based gas measurements and seismic data, we speculate that fusion of other satellite data (e.g., thermal IR; Harris et al., 2000; Wright et al., 2004) with the OMI measurements might be particularly fruitful.

\section{Acknowledgements}

We acknowledge NASA funding of $\mathrm{OMI} \mathrm{SO}_{2}$ product development and analysis (award nos. NNS06AA05G, NNG06GJ02G, and NNG06GI00G). Data used in this paper were produced by NASA in collaboration with the Royal Dutch Meteorological Institute (KNMI) in the Netherlands. The OMI project is managed by the Netherlands Agency for Aerospace Programs (NIVR) and KNMI. 


\section{References}

Afe, O.T., Richter, A., Sierk, B., Wittrock, F., Burrows, J.P., 2004. BrO emission from volcanoes: a survey using GOME and SCIAMACHY measurements. Geophys. Res. Lett. 31, L24113, doi:10.1029/2004GL020994.

Carn, S.A., Krueger, A.J., Bluth, G.J.S., Schaefer, S.J., Krotkov, N.A., Watson, I.M., Datta, S. 2003. Volcanic eruption detection by the Total Ozone Mapping Spectrometer (TOMS) instruments: a 22-year record of sulfur dioxide and ash emissions. In: Volcanic Degassing (eds. C. Oppenheimer, D.M. Pyle and J. Barclay), Geological Society, London, Special Publication 213, pp.177-202.

Cortés, G.P.J., Raigosa, J.A., 1997. A synthesis of the recent activity of Galeras volcano, Colombia: seven years of continuous surveillance, 1989-1995. J. Volcanol. Geotherm. Res. 77, 101-114.

Fischer, T.P., Morrissey, M.M., Calvache, M.L., Gómez, D., Torres, R., Stix, J., Williams, S.N., 1994. Correlations between $\mathrm{SO}_{2}$ flux and long-period seismicity at Galeras volcano. Nature 368, 135-137.

Hall, M., Ramón, P., Mothes, P., LePennec, J.-L., Garcia, A., Samaniego, P., Yepes, H., 2004. Volcanic eruptions with little warning: the case of Volcán Reventador's surprise November 3, 2002 eruption. Revista Geológica de Chile 31, 349-358.

Harris, A.J.L., Flynn, L.P., Dean, K., Pilger, E., Wooster, M., Okubo, C., Mouginis-Mark, P., Garbeil, H., Thornber, C., De La Cruz-Reyna, S., Rothery, D., Wright, R., 2000. Realtime satellite monitoring of volcanic hot spots. In: Remote Sensing of Active Volcanism (eds. P.J. Mouginis-Mark, J.A. Crisp, and J.H. Fink), American Geophysical Union, Geophysical Monograph 116, pp. 139-159. 
Johnson, J.B., Ruiz, M.C., Lees, J.M., Ramon, P., 2005. Poor scaling between elastic energy release and eruption intensity at Tungurahua Volcano, Ecuador. Geophys. Res. Lett. 32, L15304, doi:10.1029/2005GL022847.

Khokhar, M.F., Frankenburg, C., van Roozendael, M., Beirle, S., Kühl, S., Richter, A., Platt, U., Wagner, T., 2005. Satellite observations of atmospheric $\mathrm{SO}_{2}$ from volcanic eruptions during the time-period of 1996-2002. Advances in Space Research 36, 879-887.

Krotkov, N.A., Carn, S.A. , Krueger, A.J., Bhartia, P.K., Yang, K., 2006. Band residual difference algorithm for retrieval of $\mathrm{SO}_{2}$ from the Aura Ozone Monitoring Instrument (OMI). IEEE. Trans. Geosci. Remote Sensing 44(5), 1259-1266.

Krueger, A.J., Walter, L.S., Schnetzler, C.C., Doiron, S.D., 1990. TOMS measurement of the sulfur dioxide emitted during the 1985 Nevado del Ruiz eruptions. J. Volcanol. Geotherm. Res. 41, 7-15.

Krueger, A.J., Walter, L.S., Bhartia, P.K., Schnetzler, C.C., Krotkov, N.A., Sprod, I., Bluth, G.J.S., 1995. Volcanic sulfur dioxide measurements from the total ozone mapping spectrometer instruments, J. Geophys. Res. 100(D7), 14057-14076.

Krueger, A.J., Schnetzler, C.C., Walter, L.S., 1996. The December 1981 eruption of Nyamuragira volcano (Zaire), and the origin of the 'mystery cloud' of early 1982. J. Geophys. Res. 101(D10), 15191-15196.

Levelt, P.F., van den Oord, G.H.J., Dobber, M.R., Mälkki, A., Visser, H., de Vries, J., Stammes, P., Lundell, J.O.V., Saari, H., 2005a. The Ozone Monitoring Instrument. IEEE. Trans. Geosci. Remote Sensing 44(5), 1093-1101.

Levelt, P.F., Hilsenrath, E., Leppelmeier, G.W., van den Oord, G.H.J., Bhartia, P.K., Tamminen, J., de Haan, J.F., Veefkind, J.P., 2005b. Science objectives of the Ozone Monitoring Instrument. IEEE. Trans. Geosci. Remote Sensing 44(5), 1199-1208. 
Monzier, M., Robin, C., Samaniego, P., Hall, M.L., Cotten, J., Mothes, P., Arnaud, N., 1999. Sangay volcano, Ecuador: structural development, present activity and petrology. J. Volcanol. Geotherm. Res. 90, 49-79.

Ruiz, M.C., Lees, J.M., Johnson, J.B., 2006. Source constraints of Tungurahua volcano explosion events. Bull. Volcanol. 68, 480-490.

Smithsonian Institution, 1991. Nevado del Ruiz. Bulletin of the Global Volcanism Network 16(9).

Smithsonian Institution, 1996. Sangay. Bulletin of the Global Volcanism Network 21(3).

Smithsonian Institution, 1999. Guagua Pichincha. Bulletin of the Global Volcanism Network 24(9).

Smithsonian Institution, 2004. Reventador. Bulletin of the Global Volcanism Network 29(11).

Smithsonian Institution, 2005a. Fernandina. Bulletin of the Global Volcanism Network 30(4).

Smithsonian Institution, 2005b. Reventador. Bulletin of the Global Volcanism Network 30(5).

Smithsonian Institution, 2005c. Tungurahua. Bulletin of the Global Volcanism Network 30(6).

Smithsonian Institution, 2005d. Reventador. Bulletin of the Global Volcanism Network 30(8).

Smithsonian Institution, 2005e. Galeras. Bulletin of the Global Volcanism Network 30(9).

Smithsonian Institution, 2005f. Sierra Negra. Bulletin of the Global Volcanism Network 30(10).

Smithsonian Institution, 2006a. Galeras. Bulletin of the Global Volcanism Network 31(1).

Smithsonian Institution, 2006b. Sangay. Bulletin of the Global Volcanism Network 31(4). 
Smithsonian Institution, 2006c. Galeras. Bulletin of the Global Volcanism Network 31(7).

Smithsonian Institution, 2006d. Tungurahua. Bulletin of the Global Volcanism Network 31(7).

Stix, J., Zapata, J.A., Calvache, M., Cortés, G.P., Fischer, T., Gómez, D., Narváez, L., Ordóñez, M., Ortega, A., Torres, R., Williams, S.N., 1993. A model of degassing at Galeras volcano, Colombia, 1988-1993. Geology 21(11), 963-967.

Stix, J., Torres, R., Narváez, L., Cortés, G.P., Raigosa, J., Gómez, D., Castonguay, R., 1997. A model of vulcanian eruptions at Galeras volcano, Colombia. J. Volcanol. Geotherm. Res. $77,285-303$.

Tupper, A., Carn, S., Davey, J., Kamada, Y., Potts, R., Prata, F., Tokuno, M., 2004. An evaluation of volcanic cloud detection techniques during recent significant eruptions in the western 'Ring of Fire'. Remote Sens. Environ. 91, 27-46.

Whymper, E., 1892. Travels Amongst the Great Andes of the Equator. Peregrine-Smith, Salt Lake City.

Williams, S.N., Sturchio, N.C, Calvache, M.L., Mendez, R., Londoño, A., García, N., 1990. Sulfur dioxide from Nevado del Ruiz volcano, Colombia: total flux and isotopic constraints on its origin. J. Volcanol. Geotherm. Res. 42, 53-68.

Wright, R., Flynn, L.P., Garbeil, H., Harris, A.J.L., Pilger, E., 2004. MODVOLC: near-real-time thermal monitoring of global volcanism. J. Volcanol. Geotherm. Res. 135, 29-49.

Zapata, J.A., Calvache, M.L., Cortés, G.P., Fischer, T.P., Garzon, G., Gómez, D., Narváez, L., Ordóñez, M., Ortega, A., Stix, J., Torres, R., Williams, S.N., 1997. $\mathrm{SO}_{2}$ fluxes from 
Galeras Volcano, Colombia, 1989-1995: progressive degassing and conduit obstruction of a Decade Volcano. J. Volcanol. Geotherm. Res. 77, 195-208. 
Table 1. Significant eruptions in Ecuador and the Galápagos Islands since September 2004

\begin{tabular}{lllll}
\hline Volcano & Date & Duration $^{\mathrm{a}}$ & ${\text { Plume altitude }(\mathrm{km})^{\mathrm{a}}}$ & $\mathrm{SO}_{2}$ production $(\mathrm{kt})$ \\
\hline Fernandina & 13 May 2005 & 3 days? & 9 & 80 \\
Sierra Negra & 22 Oct 2005 & 8 days & $>15^{\mathrm{b}}$ & $2000^{\mathrm{c}}$ \\
Tungurahua & 14 Jul 2006 & 1 day & $15-16$ & 12 \\
Tungurahua & 16 Aug 2006 & 7 hours & $15-16$ & 35 \\
\hline
\end{tabular}

${ }^{a}$ Data sources: Smithsonian Institution (2005a, 2005f, 2006d)

${ }^{\mathrm{b}}$ Refers to the initial eruption column; most subsequent emissions were at $\sim 3-5 \mathrm{~km}$ altitude.

${ }^{c}$ Preliminary estimate using the procedure described by Krueger et al. (1996) to account for residual $\mathrm{SO}_{2}$ during effusive eruptions. 


\section{Figure captions}

Figure 1. Maps of monthly average $\mathrm{SO}_{2}$ column amounts measured by OMI over Ecuador and $\mathrm{S}$. Colombia, September 2004 - September 2006. All maps use the same color scale. The volcanoes marked on the maps are, from north to south: Galeras, Reventador, Guagua Pichincha, Tungurahua and Sangay. Date ranges span the entire month unless stated; the number of daily measurements used to calculate each average is given in parentheses after the date. (a) 6-30 Sep 2004 (14); (b) Oct 2004 (30); (c) 1-18 Nov 2004 (17); (d) 2-31 Dec 2004 (29); (e) Jan 2005 (30);

(f) Feb 2005 (27); (g) Mar 2005 (29); (h) Apr 2005 (28); (i) May 2005 (30); (j) Jun 2005 (29); (k) Jul 2005 (30); (1) Aug 2005 (31); (m) Sep 2005 (29); (n) Oct 2005 (30); (o) Nov 2005 (29); (p) Dec 2005 (30); (q) Jan 2006 (30); (r) 1-27 Feb 2006 (26); (s) 3-31 Mar 2006 (29); (t) Apr 2006 (30); (u) May 2006 (31); (v) Jun 2006 (29); (w) Jul 2006 (30); (x) Aug 2006 (30); (y) Sep 2006 (29).

Figure 2. Daily $\mathrm{SO}_{2}$ burdens (kilotons; black bars) measured by OMI over Ecuador and $\mathrm{S}$. Colombia, September 2004 - September 2006. The geographic region used to derive burdens is represented by the maps in Fig. 1. OMI data gaps of $>1$ day are denoted by vertical gray bars. Note variable scale on the ordinate. (a) $\mathrm{SO}_{2}$ burdens calculated using the FT method (see text for description of methods). Crosses show the results of automated identification of the source of the strongest $\mathrm{SO}_{2}$ emissions on each day (Gal: Galeras; Rev: Reventador; Tun: Tungurahua; San: Sangay). $\mathrm{SO}_{2}$ burdens over Ecuador impacted by three eruptions outside the region are indicated (F: Fernandina; $S N$ : Sierra Negra; $S H V$ : Soufriere Hills, Montserrat); (b) $\mathrm{SO}_{2}$ burdens calculated using the BS method. The background regions used were: $5^{\circ}-10^{\circ} \mathrm{S}, 75^{\circ}-85^{\circ} \mathrm{W}$ (northern Peru) and $5^{\circ}-10^{\circ} \mathrm{N}, 85^{\circ}-95^{\circ} \mathrm{W}$ (E. Pacific Ocean). The gray curve shows average reflectivity at $331 \mathrm{~nm}$ for the volcanic region, smoothed using a 7-day moving average, which indicates cloud cover; (c) $\mathrm{SO}_{2}$ burdens calculated using the VT method. The background regions used to assess noise were: 
$5^{\circ}-13^{\circ} \mathrm{S}, 65^{\circ}-75^{\circ} \mathrm{W}$ (northern Peru/Brazil) and $7^{\circ}-15^{\circ} \mathrm{S}, 80^{\circ}-90^{\circ} \mathrm{W}$ (E. Pacific Ocean). The gray curve shows $\mathrm{SO}_{2}$ fluxes from Tungurahua measured using ground-based differential optical absorption spectroscopy (DOAS), smoothed using a 3-day moving average. $\mathrm{SO}_{2}$ burdens impacted by three eruptions outside the region are indicated as in (a). 


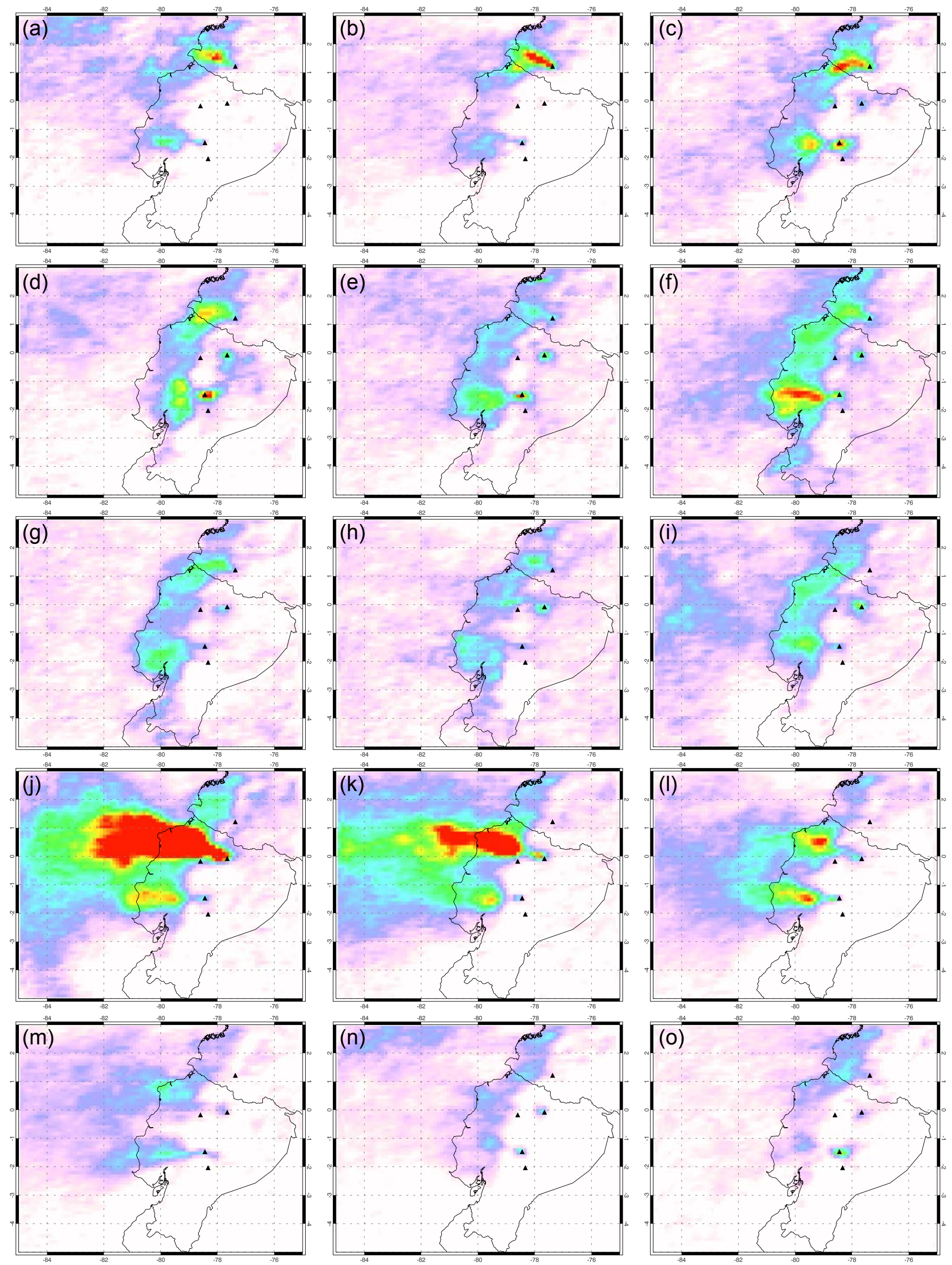

Figure 1. (part 1) 


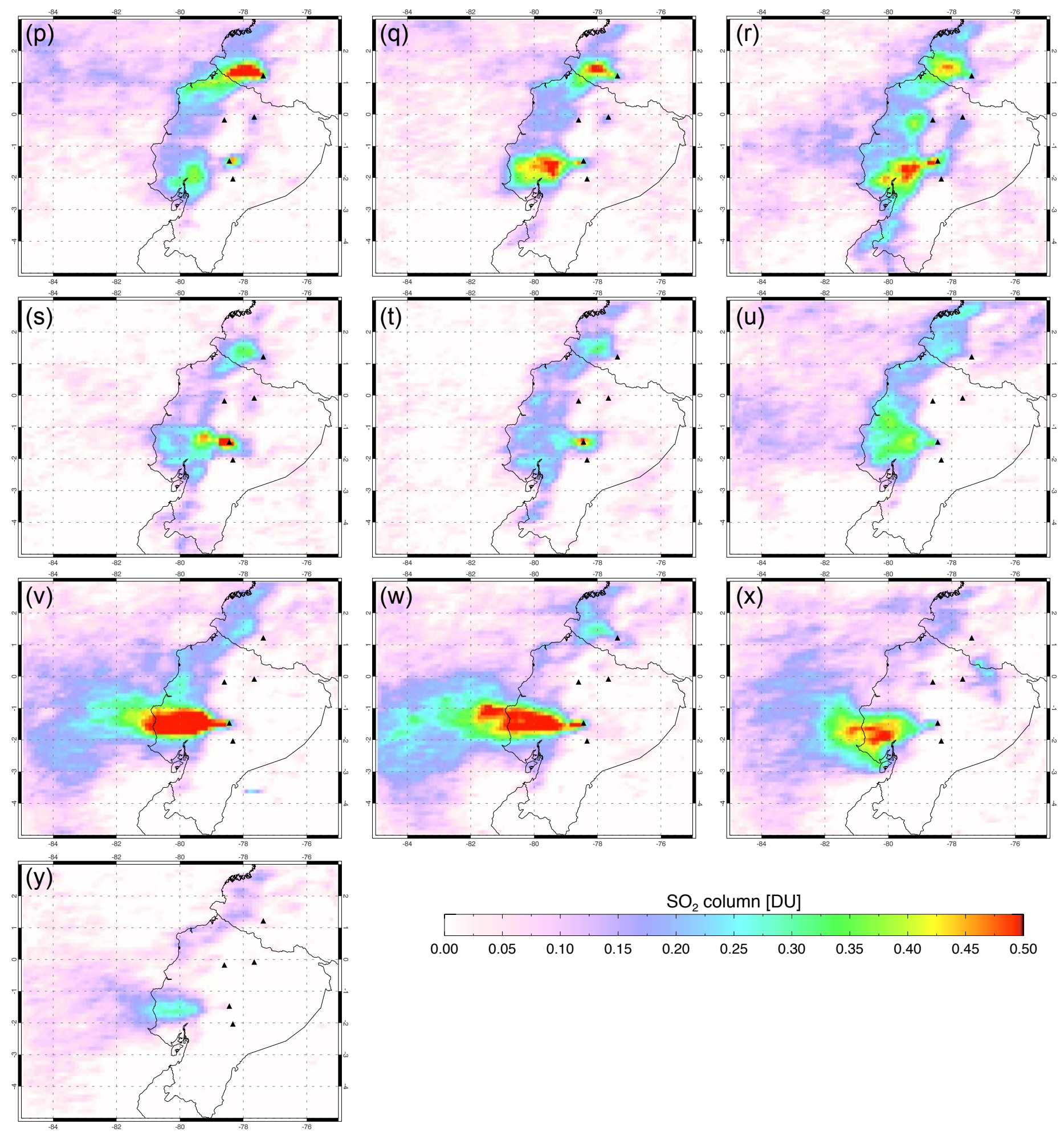

Figure 1. (part 2) 

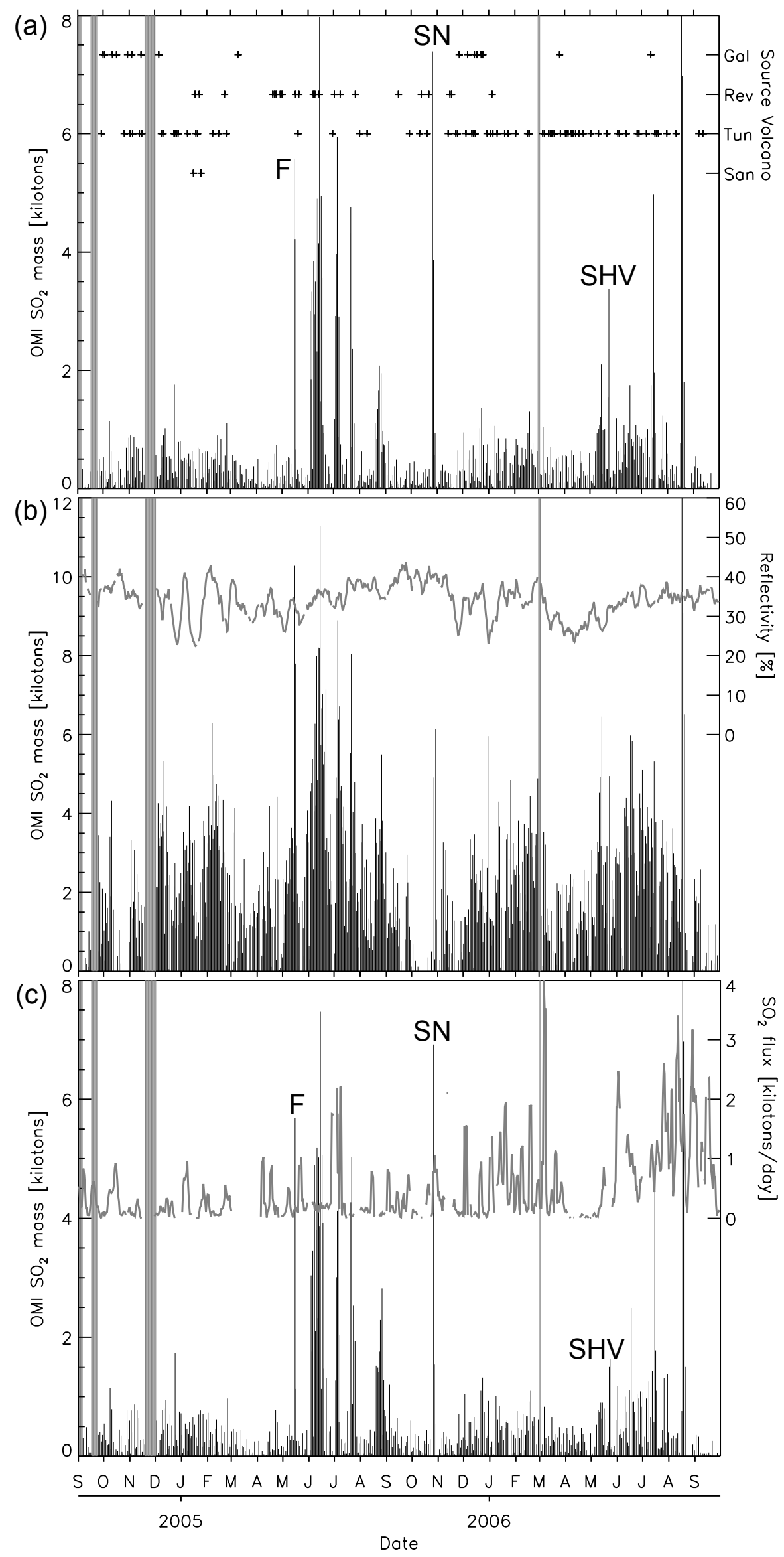

Figure 2. 